\title{
Pathophysiology of the Small Airways in Chronic Obstructive Pulmonary Disease
}

\author{
Simonetta Baraldo Graziella Turato Marina Saetta \\ Department of Cardiac, Thoracic and Vascular Sciences, Respiratory Diseases Clinic, University of Padova, \\ Padua, Italy
}

\section{Key Words}

Airway remodeling $\cdot$ Smoking $\cdot$ Inflammation

\begin{abstract}
Chronic obstructive pulmonary disease (COPD) is characterized by a persistent airflow limitation that is usually progressive and associated with an enhanced chronic inflammatory response in the airways and the lung to noxious particles or gases. From a pathological point of view, COPD is characterized by two distinct and frequently coexisting aspects: small airway abnormalities and parenchymal destruction (or emphysema). When pathological changes are localized in lung parenchyma, they will contribute to airflow limitation by reducing the elastic recoil of the lung through parenchymal destruction, as well as by reducing the elastic load applied to the airways through destruction of alveolar attachments. Conversely, when pathological changes involve the small airways, they will contribute to airflow limitation by narrowing and obliterating the lumen and by actively constricting the airways, therefore increasing the resistance. In this article we will review the structural abnormalities in small airways and their relationship with the disordered pulmonary function in COPD, in the attempt to disentangle the mechanisms contributing to the development and progression of airflow limitation in smokers. We will start by describing the normal structure of the small airways, and then observe the main pathological alterations that accumulate in this site and how they parallel pulmonary function derangement.
\end{abstract}

Copyright $\odot 2012$ S. Karger AG, Basel
(C) 2012 S. Karger AG, Basel

$0025-7931 / 12 / 0842-0089 \$ 38.00 / 0$

Fax +4161306 1234

E-Mail karger@karger.ch

www.karger.com
Accessible online at: www.karger.com/res
The pathology of chronic obstructive pulmonary disease (COPD) encompasses a variety of structural alterations which involve the airways, the lung parenchyma and the pulmonary vasculature [1]. These pathological lesions in the different compartments of the lung have been correlated with the clinical presentation and the changes in pulmonary function tests. In particular, the pioneer work by Hogg et al. [2], using the retrograde catheter technique, established the still-prevailing concept that the peripheral airways area is the major site of increased resistance in smokers, and that significant increases in these airways can be present without changes in total airway resistance. Since then, the study of small airways (or peripheral airways, i.e. noncartilaginous airways with an internal diameter of $2 \mathrm{~mm}$ or less) has been an area of intense research, going through cyclical periods of neglect and reappraisal [3-5]. The interest in the small airways has generated new and important knowledge about their pathophysiology, function and the different mechanisms involved in the development of airflow limitation in smokers. Much more is still to be discovered about the pathways through which cigarette smoke can damage the airways, but with the new tools available for the investigation of physiological and bio-

Previous articles in this series: 1. Usmani OS: Unravelling the small airways: structure-function-treatment relationships in asthma and COPD. Respiration 2012;84:1-3. 2. Hamid Q: Pathogenesis of small airways in asthma. Respiration 2012;84:4-11. 
molecular features, significant advancements are to come. We will start this review by describing the normal structure of the small airways, how this is reached through the developmental growth of the lung and how it is modified by the insult from cigarette smoke. Finally, we will see how the main pathological alterations induced in the small airways parallels the derangement of pulmonary function in smokers with COPD.

\section{Normal Airway Structure}

\section{Lung Development}

The definitive structure of the lung is achieved through a complex developmental process that, far from being complete at birth, proceeds during childhood and probably even continues during adolescence [6-10]. This has important clinical implications: on the one hand, the developing lungs may have the potential to recover from early-life insults and respond to therapies. On the other hand, environmental exposure, including cigarette smoking, can adversely affect lung growth throughout childhood.

The lungs start to develop around the 26th day of gestation as a ventral diverticulum sprouting from the foregut, in a process called branching morphogenesis. An embryogenic stage of development will follow, which is characterized by organogenesis and the appearance of the first airways and is considered to be complete between the 5th and 7th week. After that, proper fetal development starts, which is divided into 4 overlapping phases [7]:

- the pseudoglandular phase (weeks 5-17), during which the beginnings of a bronchial tree are created

- the canalicular phase (weeks 16-26), with extension of the bronchial tree, epithelial differentiation, formation of the air-blood barrier and surfactant deposition

- the saccular phase (weeks 24-38), in which the expansion of the airspaces takes place

- the alveolar phase, which begins in the last weeks of pregnancy and continues into childhood, during which alveolarization continues and maturation of the capillary bed into the alveolar wall takes place [8].

So, in a newborn baby, only a small proportion of the alveoli found in the adult lung are present and the peripheral airways, though definite in number, are still relatively short. The subsequent growth of peripheral airways is of great importance in the process of lung maturation and in the manifestation of lung diseases in childhood. In fact, while there is a proportional growth of the airways and the surrounding lung parenchyma in children older than 5 years, the peripheral airways grow at slower rates than the parenchyma (disynaptic growth) in younger children [11, 12]. This effect is observed particularly in males that have larger lung volumes but narrower airways [13]. The lack of collateral ventilation in the lungs of young children is also a major factor contributing to the severity of lung disease at this age. In an adult lung, collateral ventilation is essential to allow the flow of air between adjacent alveoli that maintains an equal level of air pressure throughout the lung and prevents overinflation. Collateral ventilation requires the presence of small holes in the alveolar walls (pores of Kohn) and/or small channels connecting preterminal bronchioli to neighboring alveoli [14]. These structures develop from the age of 6 years onward, so that younger children are at a higher risk of severe manifestations of lung disease $[15,16]$. Finally, the changes in shape, compliance and deformability of the ribcage which accompany the somatic growth also profoundly affect the physiology of the respiratory system. As a consequence of the highly compliant chest wall of the newborn, there is an increased tendency of the peripheral airways to close during tidal breathing in early infancy, which results in impaired gas exchange in the dependent parts of the lung [17]. This, together with the small absolute size of the airways, increases susceptibility to airway obstruction in the infant and small child. Thus, the complex events taking place during lung development, with a rapidly expanding lung parenchyma, narrow small airways and lack of collateral ventilation, are reflected in the manifestations of pulmonary diseases, which can be particularly severe in the first years of life. For example, bronchiolitis can be a fatal illness in infants but rarely occurs in such a severe form in the older child or adolescent. Similarly, asthma attacks in children are considerably more frequent and often more severe than those experienced by adults.

\section{Structure/Function Relationship in the Adult Lung}

As we have seen, the airway structure present in a fully grown lung is reached through a series of consecutive divisions: at each division point, or generation, one airway branches into two (or more) smaller airways. There are an estimated 23-27 airway generations in humans. The process of branching in humans is irregular, with an asymmetric dichotomy which is due to the variation in both branch diameters and in the number of divisions [7, 8]. This asymmetry originates a number of anatomical variants in the structure of the tracheobronchial tree which can be observed at bronchoscopic examination. 
Starting from the trachea, the divisions comprise the main bronchi, the lobar bronchi, the segmental bronchi and so on, up to the smallest bronchioles in the lung periphery that open into the alveolar spaces (respiratory bronchioles and alveolar ducts). The diameter of each new generation of airways decreases progressively from the trachea outwards; however, due to the exponential increase in their numbers, the airway cross-sectional area steadily enlarges throughout successive levels of branching of the bronchial system. This effect is particularly marked in the distal areas, where branching is accompanied by practically no decrease in the diameter of new generations [9-11]. The increase in sectional area means that the velocity of airflow must be sharply reduced as the airstream moves peripherally through the airways. Accordingly, the patterns of flow differ substantially from central to peripheral airways, being turbulent in larger airways and the trachea and becoming laminar towards the lung periphery [18].

The fundamental function of the bronchial tree is to move air in and out of the lung, allowing the air to reach the alveolar surface where gas transfer occurs. The inspired air should be distributed evenly to the alveolar capillary bed with minimal resistance to flow. The conducting zone of the lungs includes the trachea, bronchi and nonalveolated bronchioles, in which air cannot diffuse through the thick airway wall. Gas exchange between the oxygenated inspired air and the gas dissolved in pulmonary capillaries begins at the levels of the respiratory bronchioles, where airway walls are much thinner, and progresses into the alveolar ducts and alveolar sacs.

The airway resistance depends upon the number, length and cross-sectional area of the conducting airways. The number of airways in the normal lung is determined by the pattern of branching during development. The length of airways varies considerably from person to person depending upon age and body size; airway length also varies in an individual depending upon the phase of ventilation, lengthening during inspiration as lung volume increases and shortening during expiration. However, the cross-sectional area within the tracheobronchial tree is by far the most important determinant of airway resistance. The cross-sectional area of any given airway is determined by the balance between opposing forces: those tending to narrow the airway lumen (primarily the force generated by airway smooth muscle) and those tending to enlarge it (the indirect effects of pleural pressure in the intrapulmonary conducting airways or the direct effect of the attached lung parenchyma in the terminal bronchioles).

Small Airway Pathophysiology in COPD
Beyond gas conduction, the bronchial tree performs many other functions, such as conditioning the inspired air and remove the pollutants before they reach the respiratory portion of the lung. The effectiveness of the airways, in this respect, depends partly on their branching pattern, the composition and integrity of their structural components and the interaction of their diverse structural, immunocompetent and neural elements.

In the fully developed lung, airway wall structure and its interactions with the surrounding parenchyma are optimized to facilitate airflow and maintain airway patency. Chronic exposure to cigarette smoke has a significant impact on the structure of the small airways.

\section{Effect of Cigarette Smoking on the Structure of Small Airways}

Cigarette smoking is the most important risk factor for the development of COPD, and it has been demonstrated that cigarette smoke can induce pathological changes in the small airways even in smokers who have not developed airflow limitation [19].

One of the earliest histological abnormalities that can be detected in cigarette smokers is the presence of an inflammatory reaction in the peripheral airways. Indeed, Niewoehner et al. [20] were the first to demonstrate that an inflammatory reaction is already present in the respiratory bronchioles of young smokers who experienced sudden death outside the hospital, supporting the idea that early pathological changes may occur in the peripheral airways of smokers before COPD is established. This inflammatory reaction consisted predominantly of the infiltration of mononuclear cells in the airway wall and clusters of macrophages into the airway lumen. Interestingly, the authors reported that these lesions were present in the absence of any noteworthy tissue destruction and fibrosis, and suggested that this stage of the disease could still be largely reversible. It is conceivable that this early inflammatory infiltrate which has been observed in smokers' airways, probably represents a nonspecific response to the insult from cigarette smoke. Each puff of a cigarette contains more than 2,000 xenobiotic compounds and $10^{15}$ free radicals, which increases the oxidant burden in the lung. This burden, associated with the decrease in endogenous antioxidant defenses which occurs with aging, will result in reduced protection against oxidative stress and increased damage to lung epithelial cells and connective tissue proteins [21]. The products released during this process may possibly activate the

Respiration 2012;84:89-97 
Table 1. Inflammatory cells infiltrating the peripheral airways

\begin{tabular}{lll}
\hline & $\begin{array}{l}\text { Smokers } \\
\text { with COPD }\end{array}$ & $\begin{array}{l}\text { Smokers } \\
\text { without COPD }\end{array}$ \\
\hline CD8+ T lymphocytes & +++ & + \\
CD4+ T lymphocytes & ++ & + \\
B lymphocytes & +++ & + \\
Macrophages & ++ & + \\
Neutrophils* & ++ & + \\
Mast cells** & ++ & + \\
Eosinophils & + & + \\
Lymphoid follicles & $+* *$ & \\
\hline
\end{tabular}

From references [24, 30-32, 34, 35, 38, 41].

* Mainly in the airway lumen and during exacerbations.

** Particularly in patients with centrilobular emphysema.

*** Mainly in patients with severe disease.

immune system. Indeed, as suggested by Matzinger [22], even in the case of an infection, it is the tissue damage that is associated with the infection that will alert the immune system to respond, rather than the microbial antigens themselves. Tissue damage with the resulting cellular stress will cause the release of endogenous damageassociated molecular pattern (DAMP) molecules, such as alarmins, which alert the host to danger by triggering immune responses and activating repair mechanisms through their interaction with pattern recognition receptors. Among these danger signals, high-mobility group box 1 (HMGB1) and the receptor for advanced glycation end products (RAGE) are upregulated in the lungs of smokers and have the potential to activate an immune response by interacting with Toll-like receptors [23].

The relationship between the pathological lesions in small airways and the functional abnormalities in smokers has been investigated further by Cosio et al. [24], who developed a pathological score to describe the microscopic changes in peripheral airways. This score included the quantification of luminal occlusion, goblet-cell metaplasia, squamous-cell metaplasia, muscle hypertrophy, inflammatory cell infiltrate and fibrosis of the airway wall. The most frequently observed abnormalities of the small airways were changes in the epithelium, with squamousand goblet-cell metaplasia, together with a chronic inflammatory infiltrate, an increase of the amount of connective and airway smooth-muscle tissue. Moreover, the pathological score correlated with functional measurements reflecting small airway abnormalities (closing volume and volume of isoflow) and other function tests, e.g.
$\mathrm{FEV}_{1} / \mathrm{FVC}$, mid-flow rate and residual volume, indicating that pulmonary function progressively deteriorated as the score for the morphological abnormalities increased.

\section{Structure of the Small Airways in Established COPD}

In smokers, the establishment of COPD is associated with a further increase of this inflammatory response, which is paralleled by the development of structural abnormalities in both airway walls and lung parenchyma $[25,26]$. The recognition that inflammation plays a key role in the pathogenesis of COPD is now so widespread that it has led to the inclusion of the concept in the disease definition. Indeed, COPD is defined as a 'common, preventable and treatable disease, characterized by persistent airflow limitation that is usually progressive and associated with an enhanced chronic inflammatory response in the airways and the lung to noxious particles or gases'. Exacerbations and comorbidities contribute to the overall severity in individual patients [1]. So, although this review focused on the role of small airways, we should not forget the important interplay between pulmonary factors and extrapulmonary conditions in the ageing population [27]. Indeed, it is increasingly recognized that many patients with COPD have concomitant chronic diseases (comorbidities) that often have a major impact onthe severity of the clinical manifestations and their quality of life and survival [28]. On the one hand, comorbidities may dramatically affect deterioration of symptoms and health status in patients with COPD; conversely, airflow limitation, and particularly hyperinflation and gas exchange abnormalities, may considerably affect cardiac function. It is important to highlight that inflammation is not confined within the lung in patients with COPD, and increased levels of inflammatory mediators in the circulation may contribute to worsening comorbidities such as ischemic heart disease, heart failure, anemia, metabolic syndrome, renal disease and depression [29]. Furthermore, the presence of chronic inflammation may be a key element in the association between COPD and lung cancer, one of the most frequent comorbidities and cause of death in patients with COPD [30]. The mechanisms connecting the systemic inflammation to local responses within the lung are as of yet poorly understood, but this is an area of intense research where important advances are eagerly expected. 
In the peripheral airways of smokers with established COPD, several pathological changes have been described that can result in the narrowing of the airway lumen and the loss of the tethering function of the lung parenchyma, thus promoting a reduction of expiratory flow. These pathological lesions include an inflammatory cell infiltrate, goblet-cell metaplasia, squamous-cell metaplasia, fibrosis and an increased smooth-muscle mass, due to hypertrophy and hyperplasia of smooth-muscle cells (tables 1,2). Each of these components will be discussed below.

\section{Inflammatory Cell Infiltrate}

The characterization of the inflammatory cell subtypes infiltrating peripheral airways has identified differences between smokers who do or do not develop COPD. In smokers who develop COPD, there is an increase in the number of lymphocytes (particularly CD8+ T and B lymphocytes) and macrophages $[25,31,32]$. High numbers of $\mathrm{CD} 8+\mathrm{T}$ lymphocytes are present not only in the peripheral airways of smokers with COPD, but also in the central airways, in the lung parenchyma and in the adventitia of the pulmonary arterioles, suggesting it to be a consistent trait in these subjects [33-35]. The detection of increased numbers of lymphocytes, particularly CD8+ T cells, only in smokers who develop COPD, is intriguing and supports the notion that a $\mathrm{T}$ cell inflammation may be essential for the development of COPD, or in other words, only smokers who for some reason develop a $\mathrm{T}$ lymphocyte inflammation would develop COPD. If this were the case, an immunological reaction developing in some smokers might be the turning point from early nonspecific inflammation to subclinical and then clinical COPD [19].

Inflammation, per se, may be responsible for mild airflow limitation, and it has been suggested that it may lead to functional bronchiolar constriction by releasing mediators of inflammation that may act directly on bronchiolar smooth muscle. Chronic inflammation would, in turn, produce other changes, such as fibrosis of the airway, and could increase the smooth muscle - either directly as a result of inflammation or indirectly as a result of chronically increased muscle tone. These changes, by increasing the thickness of the airway wall, will promote airway narrowing and airflow limitation. Finally, inflammation of the airway could play an important role in the destruction of the alveolar walls attached to the airway (alveolar attachments), and the decrease in these attachments would contribute further to airflow limitation by deforming and narrowing the airway lumen.
Table 2. Structural changes in peripheral airways

\begin{tabular}{lll}
\hline & $\begin{array}{l}\text { Smokers } \\
\text { with COPD }\end{array}$ & $\begin{array}{l}\text { Smokers } \\
\text { without } \\
\text { COPD }\end{array}$ \\
& & + \\
\hline Luminal occlusion* & +++ & + \\
Goblet-cell metaplasia & ++ & + \\
Squamous-cell metaplasia & ++ & \\
Muscle hypertrophy and hyperplasia & ++ & + \\
Fibrosis & ++ & + \\
Total wall thickening & +++ & + \\
Loss of alveolar attachments & +++ & \\
& & + \\
\hline
\end{tabular}

From references [23, 24, 31, 35, 39, 44, 45].

* Mainly in patients with bronchitis.

\section{Epithelial and Lumen Abnormalities}

The epithelial layer plays an extremely important role in the normal function and regulation of the airways. Cigarette smoking can damage the airway epithelium, inducing mucosal ulcers and squamous- and goblet-cell metaplasia [24]. A significantly increased number of mucus-secreting goblet cells can be seen in the peripheral airway epithelium of smokers with COPD. The increased number of goblet cells correlates with the degree of lung function impairment, as assessed by $\mathrm{FEV}_{1} / \mathrm{FVC}$ [36]. This goblet-cell metaplasia can have important functional consequences, potentially contributing to the development of smoking-induced airflow obstruction in at least two ways: first, by producing an excess of mucus which could alter the surface tension of the airway lining fluid, rendering the peripheral airways unstable and facilitating their closure [4] and second, by inducing luminal occlusion through the formation of mucous plugs in the peripheral airways [24]. Indeed, luminal occlusion by mucous and inflammatory exudate plugs are frequently observed in smokers with COPD [32], and neutrophils, which are not usually found within the airway wall, are increased in their peripheral airway epithelium [36]. As neutrophil elastase is a remarkably potent secretagogue, it has been proposed that the location of neutrophils within the epithelium is crucial for the activation of the secretory function of goblet cells in smokers.

While airway obstruction may be induced by excessive mucus production from the numerous goblet cells in the peripheral airways, it remains controversial whether or not chronic bronchitis (due to mucus hypersecretion in the bronchial glands of the central airways) contributes to the development of functional abnormalities. For 


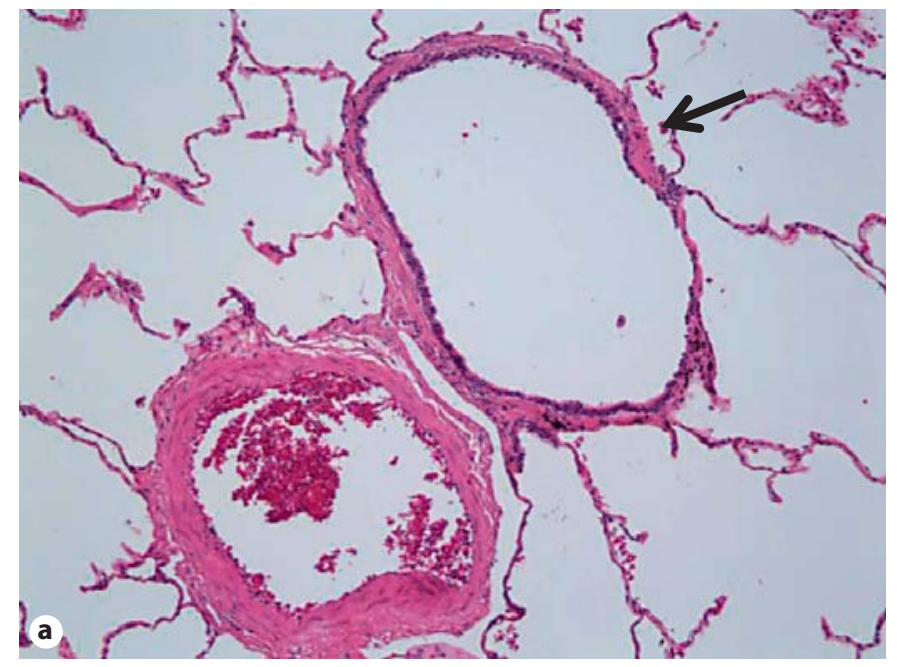

Fig. 1. Small airway morphology in a nonsmoking subject and in a COPD patient. a In the specimen from the nonsmoker, we can see a peripheral airway (arrow) adjacent to a pulmonary arteriole. Note that the airway wall is thin, the lumen is wide open and that intact alveoli are attached along its circumference. $\mathbf{b}$ In the speci-

many years, chronic bronchitis was considered irrelevant, but more recent studies have demonstrated an association between chronic mucus hypersecretion, $\mathrm{FEV}_{1}$ decline and COPD morbidity [37,38], suggesting that this clinical condition, when present, should not be ignored.

\section{Smooth Muscle Abnormalities}

When the amount of smooth muscle is measured in the peripheral airways of smokers with or without COPD, an increased area occupied by smooth muscle is found in those with COPD.

Increase in smooth muscle correlates with the degree of airflow limitation; the greater the amount of smooth muscle, the lower the $\mathrm{FEV}_{1}$ and the more severe the airway obstruction [25]. So, increased smooth-muscle mass is an important component of airway wall thickening, which can be due to several mechanisms including hypertrophy and hyperplasia, possibly due to the activity of inflammatory mediators, cytokines and growth factors. The airways of smokers can react to nonspecific stimuli by constricting, and this results in increased resistance and decreased $\mathrm{FEV}_{1}$. Whether hyperresponsiveness is a primary event that might contribute to the natural history of COPD or is a consequence of the already decreased airway dimensions is still an open question. Regardless of the mechanism, the abnormalities found in the airways of smokers, such as epithelial damage and chronic in-

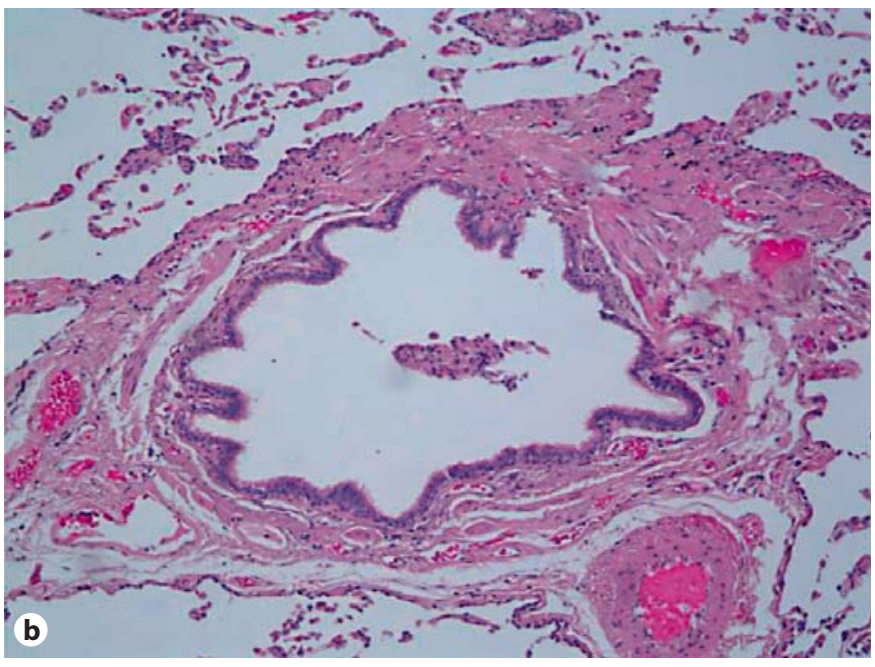

men from the smoker with COPD, the lumen of the airway is narrowed and contains mucus and cellular debris. The airway wall is thickened, with an important component of airway smooth muscle and fibrosis, and the majority of the alveolar attachments along its circumference are broken. flammation, could contribute to the constriction of even a normal airway smooth muscle [39]. The major functional consequence of the increase in smooth-muscle mass is that, in airways with thickened walls, the same degree of smooth-muscle shortening may cause considerably greater lumenal narrowing than in the normal airways [40].

\section{Peripheral Wall Fibrosis}

Another important component of remodeling is fibrosis of the airway wall. It has previously been reported that cigarette smoke induces oxidative stress in human lung fibroblasts, which may then initiate a process of repair and collagen deposition [41]. Furthermore, the interaction between fibroblasts and inflammatory cells may also play a role in fibrotic remodeling. Along with this is the observation that mast cells, which have important profibrotic and prorepair properties, are increased in the airways of smokers with COPD, particularly in those with centrilobular emphysema [42]. Fibrosis, along with an increased airway smooth muscle and other inflammatory components, ought to increase the airway wall thickness and change the mechanical characteristics of the airway to decrease the luminal diameter. That this is indeed the case was shown by Wright et al. [43] and Finkelstein et al. [44], who found that the wall thickness of membranous and respiratory bronchioles for each bronchiolar diame- 
ter was increased in almost all size ranges in smokers when compared to lifetime nonsmokers. In the context of a disease such as COPD, it is well conceivable that the pathological changes observed in small airways are associated with an attempt to repair, resulting in fibrosis and thickening of the airway wall [45]. In line with this hypothesis, Hogg et al. [32] clearly demonstrated that the total thickness of the airway wall was the parameter found to correlate best with airflow limitation in smokers across the different stages of severity of the GOLD classification.

\section{Alveolar Attachments}

Inflammation, fibrosis and smooth-muscle hypertrophy, by increasing the thickness of the airway wall, may facilitate uncoupling between airways and parenchyma, therefore promoting airway closure. In addition, airway wall inflammation could contribute to the destruction of alveolar attachments (i.e. the alveolar walls directly attached to the airway wall), further reducing the tethering effect of lung parenchyma, thus allowing the airway wall to deform and narrow (fig. 1). This hypothesis is supported by the observation that, in smokers, the destruction of alveolar attachments is correlated with the degree of inflammation in the peripheral airways [46]. This finding suggests a pathogenetic role for airway inflammation in inducing the destruction of alveolar attachments. It is possible that mediators released by inflammatory cells may weaken the alveolar tissue and facilitate its rupture, particularly at the point where the attachments join the airway wall and the mechanical stress is maximal.

\section{Small Airway Abnormalities in Severe COPD}

Once the pathological changes in the airways are established, the striking correlation between the progression of physiological impairment and the degree of small airway disease suggests that inflammation of the small airways makes an important contribution to the functional deterioration seen in COPD, even in the presence of emphysema. In patients with severe COPD, an amplification of the inflammatory response in the peripheral airways has been demonstrated, with a nearly 3 -fold increase in the number of leukocytes, particularly of T lymphocytes and macrophages, suggesting that the inflammation initiated by cigarette smoking worsens as airflow deteriorates $[47,48]$. This worsening airway inflammatory process is correlated with the degrees of airflow lim- itation, lung hyperinflation, CO diffusion impairment and radiological emphysema, suggesting a role for this inflammatory response in the clinical progression of the disease [47]. A similar amplification of the inflammatory response was observed in the lung parenchyma of patients with severe emphysema by Retamales et al. [48]. These results confirm the pioneer observations of Nagai et al. [49] in patients dying from COPD. In their study, flow rates correlated with the degree of macroscopic emphysema, but also with the degree of deformity of respiratory bronchioles, indicating that decreases in flow were secondary to both emphysema and airway obstruction. Of note in that study is that, for the same degree of airflow limitation, smokers with lesser amounts of emphysema had more diseased small airways (and vice versa), pointing to the heterogeneity of the pathophysiology of COPD, which is reflected in the heterogeneity in the clinical presentation.

Pulmonary inflammation in severe COPD includes large numbers of oligoclonal $\mathrm{T}$ lymphocytes (including both CD4+ and CD8+ cells) and B lymphocytes, which persist for years after the cessation of smoking, suggesting the presence of a self-perpetuating process $[32,47-$ 52]. Moreover, in patients in the most severe stages of COPD, inflammatory cells in the airway wall are observed in well-organized lymphoid follicles, that represent tertiary lymphoid structures specialized in antigen presentation [32]. Sequence analysis of rearranged immunoglobulin genes in individual B cell clones in these lymphoid follicles revealed the presence of clonally related B cells, suggesting an antigen-driven selection process. Some authors suggested that these follicles represent an adaptive immune response which may develop in relation to microbial colonization and infection, which are a frequent occurrence in the later stages of COPD [32]. However, the absence of bacterial and viral products in the follicles prompts other authors to suggest that these oligoclonal B cells may arise in response to lung auto-antigens [52]. Indeed, there is increasing evidence that autoimmunity may play a role in the pathogenesis of COPD. This hypothesis was first raised based on the observation that lymphocytes are the predominant cells infiltrating the lung tissue of patients with COPD and that their numbers are strongly related to the apoptosis of structural cells and lung function impairment. Currently, there is circumstantial, indirect and direct evidence of the involvement of cellular and humoral immune responses in the lung damage of COPD, possibly supported by the recognition of pulmonary self-antigens modified by cigarette smoking and 
the failure of mechanisms regulating immunological tolerance [19]. Nevertheless, no direct cause-effect relationship linking COPD to autoimmune damage has of yet been established, and further studies are required to investigate this important issue.

In conclusion, in this review we have seen how the normal structure of the small airways is reached through development, how it is affected by the insult from cigarette smoke and how it is further modified in parallel with the establishment and progression of airflow limitation. These observations highlight the complexity of COPD and its pathophysiology and points to the importance of studies correlating the morphology and function in COPD, the basis for our present understanding of the pathophysiology of the small airways.

\section{References}

1 The Global Strategy for the Diagnosis, Management and Prevention of COPD, Global Initiative for Chronic Obstructive Lung Disease (GOLD), 2011. http://www.goldcopd. org/.

-2 Hogg JC, Macklem PT, Thurlbeck WM: Site and nature of airway obstruction in chronic obstructive lung disease. N Engl J Med 1968 278:1355-1360.

3 Macklem PT, Mead J: Resistance of central and peripheral airways measured by a retrograde catheter. J Appl Physiol 1967;22:395401.

4 Macklem PT: The physiology of small airways. Am J Respir Crit Care Med 1998; 157:S181-S183

5 Contoli M, Bousquet J, Fabbri LM, Magnussen H, Rabe KF, Siafakas NM, et al: The small airways and distal lung compartment in asthma and COPD: a time for reappraisal. Allergy 2010;65:141-151.

6 Narayanan M, Owers-Bradley J, Beardsmore CS, Mada M, Ball I, Garipov R, et al: Alveolarization continues during childhood and adolescence: new evidence from helium-3 magnetic resonance. Am J Respir Crit Care Med 2012;185:186-191.

7 Burri PH: Postnatal development and growth; in Crystal RG, West JB (eds): The Lung: Scientific Foundations, section 4.1. New York, Raven Press, 1991, pp 677-687.

8 Thurlbeek WM: Pre- and postnatal organ development; in Chernick V, Mellins RN (eds): Basic Mechanisms of Pediatric Respiratory Disease: Cellular and Integrative. Philadelphia, Decker Inc., 1991, pp 23-25.

9 Reid L: The embryology of the lung; in de Renck AVS, Porter S (eds): Ciba Foundation: Symposium on Development of the Lung. London, Churchill, 1967, pp 109-430.

10 Plopper CG, Thurlbeck WM: Growth, ageing and adaptation; in Murray JF, Nadel JA (eds): Textbook of Respiratory Medicine. Philadelphia, WB Saunders, 1994, pp 36-49.

11 Doershuk CF, Fisher BJ, Matthews LW: Specific airway resistance from the perinatal period into adulthood. Alterations in childhood pulmonary disease. Am Rev Respir Dis 1974;109:452-457.
12 Hogg J, Williams J, Richardson J, Macklem P, Thurlbeck W: Age as a factor in the distribution of lower-airway conductance in the pathologic anatomy of obstructive lung disease. N Engl J Med 1970;282:1283-1287.

13 Hibbert M, Lannigan A, Raven J, Landau L, Phelan P: Gender differences in lung growth. Pediatr Pulmonol 1995;19:129-134.

14 Lambert MW: Accessory bronchiole-alveolar communications. J Pathol Bacteriol 1955; 70:311-314.

15 Meyrick B, Reid LM: Ultrastructure of alveolar lining and its development; in Hosdon WA (ed): Development of the Lung. Lung Biology in Health and Disease Series. New York, Marcel Dekker, 1977, pp 135-214.

16 Boyden EA: Development of the human lung; in Kelley VC (ed): Brennerman's Practice of Pediatrics, vol 4. Hagerstown, Harper and Row, 1972.

17 Frey U: Why are infants prone to wheeze? Physiological aspects of wheezing disorders in infants. Swiss Med Wkly 2001;131:400406

18 Landau LD, Lifshitz EM: Viscous fluids; in: Fluid Mechanics, ed 2. New York, Pergamon Press, 1987, pp 44-94

19 Cosio MG, Saetta M, Agusti A: Immunologic aspects of chronic obstructive pulmonary disease. N Engl J Med 2009;360:24452454.

20 Niewoehner DE, Klienerman J, Rice D: Pathological changes in the peripheral airways of young cigarette smokers. N Engl J Med 1974; 291:755-758.

-21 Yao H, Rahman I: Current concepts on oxidative/carbonyl stress, inflammation and epigenetics in pathogenesis of chronic obstructive pulmonary disease. Toxicol Appl Pharmacol 2011;254:72-85.

22 Matzinger P: Friendly and dangerous signals: is the tissue in control? Nat Immunol 2007;8:11-13

23 Ferhani N, Letuve S, Kozhich A, Thibaudeau $O$, Grandsaigne M, Maret M, et al: Expression of high-mobility group box 1 and of receptor for advanced glycation end products in chronic obstructive pulmonary disease. Am J Respir Crit Care Med 2010;181:917927.
24 Cosio MG, Ghezzo H, Hogg JC, Corbin R, Loveland M, Dosman J, et al: The relationships between structural changes in small airways and pulmonary-function tests. N Engl J Med 1977;298:1277-1281.

25 Saetta M, Di Stefano A, Turato G, Facchini FM, Corbino L, Mapp CE, et al: CD8+ Tlymphocytes in the peripheral airways of smokers with chronic obstructive pulmonary disease. Am J Respir Crit Care Med 1998; 157:822-826

26 Turato G, Zuin R, Saetta M: Pathogenesis and pathology of COPD. Respiration 2001; 68:117-128.

27 Luppi F, Franco F, Beghé B, Fabbri LM: Treatment of chronic obstructive pulmonary disease and its comorbidities. Proc Am Thorac Soc 2008;5:848-856.

28 Cazzola M, Bettoncelli G, Sessa E, Cricelli C, Biscione G: Prevalence of comorbidities in patients with chronic obstructive pulmonary disease. Respiration 2010;80:112-119.

29 van Eeden SF, Sin DD: Chronic obstructive pulmonary disease: a chronic systemic inflammatory disease. Respiration 2008;75: 224-238.

30 Rooney C, Sethi T: The epithelial cell and lung cancer: the link between chronic obstructive pulmonary disease and lung cancer. Respiration 2011;81:89-104.

- 31 Bosken CH, Hards J, Gatter K, Hogg JC: Characterization of the inflammatory reaction in the peripheral airways of cigarette smokers using immunocytochemistry. Am Rev Respir Dis 1992;145:911-917.

- 32 Hogg JC, Chu F, Utokaparch S, Woods R, Elliott WM, Buzatu L, et al: The nature of small-airway obstruction in chronic obstructive pulmonary disease. N Engl J Med 2004;350:2645-2653.

33 Saetta M, Baraldo S, Corbino L, Turato G, Braccioni F, Rea F, et al: CD8+ve cells in the lungs of smokers with chronic obstructive pulmonary disease. Am J Respir Crit Care Med 1999;160:711-717.

34 Majo J, Ghezzo H, Cosio MG: Lymphocyte population and apoptosis in the lungs of smokers and their relationship with emphysema. Eur Respir J 2001;17:946-953. 
-35 O’Shaughnessy TC, Ansari TW, Barnes NC, Jeffery PK: Inflammation in bronchial biopsies of subjects with chronic bronchitis: inverse relationship of CD8+ T lymphocytes with $\mathrm{FEV}_{1}$. Am J Respir Crit Care Med 1997; 155:852-857.

- 36 Saetta M, Turato G, Baraldo S, Zanin A, Braccioni F, Mapp CE, et al: Goblet cell hyperplasia and epithelial inflammation in peripheral airways of smokers with both symptoms of chronic bronchitis and chronic airflow limitation. Am J Respir Crit Care Med 2000;161:1016-1021.

37 Vestbo J, Prescott E, Lange P: Association of chronic mucus hypersecretion with $\mathrm{FEV}_{1}$ decline and chronic obstructive pulmonary disease morbidity. Copenhagen City Heart Study Group. Am J Respir Crit Care Med 1996;153:1530-1535.

38 Montes De Oca M, Halbert RJ, Lopez MV, Perez-Padilla R, Tálamo C, Moreno D, et al: Chronic bronchitis phenotype in subjects with and without COPD: the PLATINO study. Eur Respir J 2012, E-pub ahead of print.

-39 Baraldo S, Turato G, Badin C, Bazzan E, Beghé B, Zuin R, et al: Neutrophilic infiltration within the airway smooth muscle in patients with COPD. Thorax 2004;59:308-312.

40 Lambert RK, Wiggs BR, Kuwano K, Hogg JC, Parè PD: Functional significance of increased airway smooth muscle in asthma and COPD. J Appl Physiol 1993;74:27712781.
41 Carnevali S, Luppi F, D’Arca D, Caporali A, Ruggieri MP, Vettori MV, et al: Clusterin decreases oxidative stress in lung fibroblasts exposed to cigarette smoke. Am J Respir Crit Care Med 2006;174:393-399.

42 Ballarin A, Bazzan E, Hernandez Zenteno R, Turato G, Baraldo S, Zanovello D, et al: Mast cell infiltration discriminates between histopathological phenotypes of chronic obstructive pulmonary disease. Am J Respir Crit Care Med 2012, E-pub ahead of print, PMID: 22679009.

43 Wright JL, Hobson J, Wiggs BR, Pare PD, Hogg JC: Effect of cigarette smoking on structure of the small airways. Lung 1987; 165:91-100.

44 Finkelstein R, Fraser RS, Ghezzo H, Cosio MG: Alveolar inflammation and its relation to emphysema in smokers. Am J Respir Crit Care Med 1995;152:1666-1672.

45 Deveci F, Murat A, Turgut T, Altuntaş E, Muz MH: Airway wall thickness in patients with COPD and healthy current smokers and healthy non-smokers: assessment with high resolution computed tomographic scanning. Respiration 2004;71:602-610.

46 Saetta M, Ghezzo H, Kim WD, King M, Angus GE, Wang NS, et al: Loss of alveolar attachments in smokers: an early morphometric correlate of lung function impairment. Am Rev Respir Dis 1985;132:894-900.
7 Turato G, Zuin R, Miniati M, Baraldo S, Rea $\mathrm{F}$, Beghe B, et al: Airway inflammation in severe chronic obstructive pulmonary disease: relationship with lung function and radiologic emphysema. Am J Respir Crit Care Med 2002;166:105-110.

48 Retamales I, Elliott WM, Meshi B, Coxson HO, Pare PD, Sciurba FC, et al: Amplification of inflammation in emphysema and its association with latent adenoviral infection. Am J Respir Crit Care Med 2001;164:469473.

49 Nagai A, West WW, Paul JL, Thurlbeck WM: The National Institutes of Health Intermittent Positive Pressure Breathing trial: pathology studies. I. Interrelationship between morphologic lesions. Am Rev Respir Dis 1985;132:937-945.

50 Polverino F, Baraldo S, Bazzan E, Agostini S, Turato G, Lunardi F, et al: A novel insight into adaptive immunity in chronic obstructive pulmonary disease: B cell activating factor belonging to the tumor necrosis factor family. Am J Respir Crit Care Med 2010;182: 1011-1019.

-51 Baraldo S, Lokar Oliani K, Turato G, Zuin R, Saetta M: The role of lymphocytes in the pathogenesis of asthma and COPD. Curr Med Chem 2007;14:2250-2256.

52 Van Der Strate BWA, Postma DS, Brandsma CA, Melgert BN, Luinge MA, Geerlings M, et al: Cigarette smoke-induced emphysema: a role for the B cell? Am J Respir Crit Care Med 2006;173:751-758. 